\title{
PENGETAHUAN DAN SIKAP IBU NIFAS TENTANG TANDA BAHAYA NEONATUS DI PUSKESMAS II KARANGASEM BALI TAHUN 2013
}

\author{
I Gusti Ngurah Agung Indra Suharta ${ }^{1}$, Ketut Suarjaya ${ }^{2}$ \\ Program Studi Pendidikan Dokter Fakultas Kedokteran Universitas Udayana ${ }^{1}$ \\ Kepala Puskesmas Karangasem II Kabupaten Karangasem ${ }^{2}$
}

(adunk.indra@gmail.com)

\begin{abstract}
ABSTRAK
Angka kematian neonatus di Kabupaten Karangasem masih cukup tinggi. Angka kematian neonatus terbesar berada di Kecamatan Karangasem. Pneumonia, hipotermi, ikterus, dan neonatal tetanus merupakan beberapa penyebab kematian yang sering muncul pada neonatus. Tujuan penelitian ini adalah untuk mengetahui gambaran pengetahuan dan sikap ibu nifas tentang tanda bahaya masa neonatus. Metode penelitian deskriptif observasional dengan menggunakan pendekatan cross sectional. Jumlah sampel yang digunakan sebesar 43 orang, dengan kriteria ibu 0-28 hari post partum yang datang ke Puskesmas Karangasem II dan ibu post partum yang dirawat inap di Puskesmas Karangasem II. Penelitian ini dilaksanakan mulai bulan Juni hingga bulan Juli 2013. Hasil didapatkan ibu berpengetahuan baik, cukup dan kurang berturut-turut sebesar 51,16 persen, 37,21 persen dan 11,63 persen. Secara spesifik, pengetahuan ibu nifas kurang pada ikterus neonatorum $(69,77 \%)$ dan tetanus neonatorum $(37,21 \%)$. Selain itu sebanyak 41, 86 persen responden memiliki sikap negatif tentang tanda bahaya neonatus.
\end{abstract}

Kata kunci: Neonatus, Kematian Neonatus, Pengetahuan, Sikap

\section{ABSTRACT}

Neonatal mortality or high risk neonates in Karangasem is still high. The largest amount found in Karangasem District. Pneumonia, hipotermy, neonatal jaundice, neonatal tetanus are some causes of neonatal mortality. The purpose of this research is to determine knowledge and attitudes of post partum women about danger signs of neonatal period. Cross sectional design is used in descriptive observational research. Number of samples were 43 people, with criteria $0-28$ days post partum women who visit Puskesmas Karangasem II and post partum women who hospitalized at Puskesmas Karangasem II. This research were done for about 2 months, started from June until July 2013. Based on the results, knowledge of respondents had the most good knowledge, as much as $51,16 \%$, respondents who had enough knowledge were $37,21 \%$ and respondents who had less knowledge were $11,63 \%$. Specifically, knowledge of postpartum mother less on neonatal jaundice $(69,77 \%)$ and neonatal tetanus $(37,21 \%)$. Where as, attitude of respondents about danger signs of neonatal period which had a negative attitude as much as $41,86 \%$ respondents

Keywords : Neonatal, Neonatal mortality, Knowledge, Attitude.

\section{PENDAHULUAN}

Masa neonatus adalah masa kehidupan pertama di luar rahim sampai usia 28 hari, dimana terjadi perubahan yang sangat besar dari kehidupan di dalam rahim ke luar rahim. Semua bayi baru lahir harus diperiksa secepatnya untuk mengetahui ada tidaknya luka pada waktu dilahirkan atau kelainan bawaan. Dokter dan bidan bertanggung jawab untuk membantu bayi baru lahir, tidak hanya melewati fase kehidupan dalam rahim menuju kehidupan luar rahim seaman mungkin, tetapi juga melakukan adaptasi fisik terhadap kehidupan luar rahim ${ }^{1}$. Kematian bayi baru lahir (neonatus) merupakan penyumbang kematian terbesar pada tingginya angka kematian bayi². Berdasarkan Laporan Bulanan (LB) 3 Kesehatan Ibu dan Anak (KIA) dan Laporan Kesehatan Maternal Neonatal Tahun 2008, jumlah kematian bayi di Provinsi Bali adalah 131 orang dengan persentase 11,01 persen. Jumlah neonatus risiko tinggi/komplikasi yang tertangani di wilayah Provinsi Bali sebesar 3.285 kasus dari 6.420 kasus yang $\mathrm{ada}^{3}$. Jumlah neonatus yang termasuk dalam kategori risiko tinggi atau mengalami komplikasi di wilayah Kabupaten Karangasem pada tahun 2008 adalah sebanyak 2.254 
neonatus dan jumlah terbesar terdapat di wilayah Kecamatan Karangasem, yaitu sebanyak 468 neonatus ${ }^{4}$.

Berdasarkan hasil studi pendahuluan yang dilakukan di Puskesmas Karangasem II terhadap 10 orang ibu nifas 0-28 hari diperoleh bahwa 20 persen yang dapat menyebutkan tanda bahaya neonatus, 10 persen yang masih ragu-ragu menyebutkan tanda bahaya neonatus dan 70 persen yang sama sekali tidak dapat menyebutkan tanda bahaya neonatus. Data kematian neonatus yang didapatkan di wilayah kerja Puskesmas Karangasem II pada tahun 2009 adalah sebanyak 17 neonatus, dimana kelompok umur 0-7 hari sebanyak 15 neonatus dan kelompok umur 8 28 hari sebanyak 2 neonatus. Penyebab dari kematian neonatus ini adalah asfiksia berat $(17,6 \%)$, sepsis $(29,4 \%), \operatorname{BBLR}(29,4 \%)$ dan pneumonia $(6 \%)$.

Pengetahuan adalah hasil tahu manusia yang terjadi setelah orang melakukan penginderaan terhadap suatu objek tertentu. Penginderaan terjadi melalui panca indera manusia yakni indera penglihatan, pendengaran,penawaran rasa dan peraba $^{5}$. Pengetahuan atau kognitif merupakan domain yang sangat penting dalam membentuk sikap dan tindakan seseorang (over behavior). Domain kognitif itu adalah kawasan yang berkaitan dengan aspek-aspek intelektual atau secara logis bisa diukur dengan pikiran atau nalar. Sikap adalah reaksi atau respon seseorang yang masih tertutup terhadap suatu stimulus satu objek. Sikap terdiri dari tiga komponen pokok yaitu keyakinan (kepercayaan), ide dan konsep terhadap objek, kehidupan emosional atau evaluasi emosional terhadap objek dan kecenderungan untuk bertindak 6 .

Notoatmodjo mengatakan bahwa untuk menimbulkan suatu respon batin dalam bentuk sikap dari subjek terhadap objek yang diketahuinya, maka perlu di mulai dari domain kognitif (pengetahuan). Maksudnya adalah subjek mengetahui stimulus yang datang baik berupa materi maupun objek. Pengetahuan dan informasi sangat mempengaruhi pembentukan sikap ${ }^{7}$.

Penelitian ini bertujuan untuk mengetahui gambaran pengetahuan dan sikap ibu nifas tentang tanda bahaya neonatus, sedangkan tujuan khususnya adalah mengidentifikasi pengetahuan ibu nifas tentang tanda bahaya, dampak serta penanganan

\section{HASIL}

Lokasi penelitian beralamat di Desa Seraya Tengah, Kecamatan Karangasem. Wilayah yang menjadi lingkup kerja Puskesmas Karangasem II yaitu Desa Bunutan, Desa Seraya Timur, Desa Seraya Tengah dan Desa Seraya Barat. Jumlah penduduk di wilayah kerja Puskesmas Karangasem II tahun 2009 adalah 17.542 orang. Jumlah ibu nifas yang ada di Puskesmas Karangasem II dari tanggal 3 Juni sampai 21 Juli 2013 hipotermi, ikterus, diare, tetanus neonatorum dan pneumonia pada neonatus dan mengidentifikasi sikap ibu nifas tentang gejala dan penanganan hipotermi, ikterus, diare, tetanus neonatorum dan pneumonia pada neonatus.

\section{METODE PENELITIAN}

Penelitian ini merupakan penelitian deskriptif observasional dengan pendekatan cross sectional. Penelitian dilakukan di Puskesmas Karangasem II dari tanggal 3 Juni sampai 21 Juli 2013 dengan jumlah sampel sebanyak 43 orang. Populasi penelitian ini adalah seluruh ibu nifas yang ada di Puskesmas Karangasem II dengan unit analisis ibu nifas 0-28 hari yang datang ke Puskesmas Karangasem II serta ibu nifas yang dirawat inap di Puskesmas Karangasem Il yang memenuhi kriteria inklusi.

Penelitian dilakukan terhadap aspek pengetahun dan sikap ibu nifas tentang tanda bahaya neonatus. Peneliti menggunakan dua teknik sampling yaitu purposive sampling dan accidental sampling. Data yang dikumpulkan berupa data primer. Pengumpulan data dilakukan dengan wawancara menggunakan pedoman wawancara yang dibuat sesuai dengan konsep teori tentang tanda bahaya neonatus. Data yang telah dikumpulkan kemudian dihitung nilai masing-masing responden. Menurut Budiarto, setiap pertanyaan yang dikelompokkan ke dalam bentuk pengetahuan dihitung persentasenya dengan cara membagi frekuensi (f) dengan seluruh pertanyaan (N) kemudian dikalikan 100 persen $^{8}$. Penggolongan pengetahuan baik, cukup dan kurang berdasarkan persentase hasil dengan kriteria baik, cukup dan kurang berturut-turut lebih dari 76 persen, 56 sampai 76 persen dan kurang dari 56 persen. Data pada pedoman wawancara sikap dihitung skor total masing-masing responden. Data yang diperoleh telah dianalisis dan didapatkan data berdistribusi tidak normal sehingga digunakan nilai median untuk menentukan sikap positif atau negatif.

Langkah-langkah dalam pengumpulan data yang dilakukan yaitu mengurus izin ke tempat penelitian, mencari sampel penelitian, menjelaskan maksud dan tujuan penelitian serta pelaksanaan wawancara, penandatanganan lembar persetujuan menjadi responden dan melakukan wawancara terpimpin dengan responden.

sebanyak 73 orang, dengan rincian jumlah ibu nifas yang memenuhi kriteria inklusi sebanyak 46 orang dan yang tidak memenuhi kriteria inklusi sebanyak 27 orang.

Tenaga kesehatan yang membantu kegiatan operasional Puskesmas terdiri dari beberapa jenis yaitu dokter umum tiga orang, dokter gigi satu orang, bidan 15 orang, perawat gigi dua orang dan apoteker 
satu orang. Pengetahuan responden tentang tanda bahaya neonatus dapat dilihat pada tabel 1 .

Tabel 1 menunjukkan bahwa hampir setengah dari total responden memiliki pengetahuan kurang baik mengenai tanda bahaya neonates dan lebih dari setengah responden $(51,16 \%)$ memiliki pengetahuan baik.

Berdasarkan tabel 2 dapat dilihat bahwa sebagian kecil responden (11,63\%) memiliki pengetahuan kurang tentang hipotermi, kurang dari sepertiga responden $(23,25 \%)$ memiliki pengetahuan cukup dan sebagian besar responden (62,12\%) memiliki pengetahuan baik. Sebagian kecil responden $(2,32 \%)$ memiliki pengetahuan baik tentang ikterus, sebanyak $27,91 \%$ responden memiliki pengetahuan cukup dan sebagian besar responden (69,77\%) memiliki pengetahuan kurang. Tingkat pengetahuan responden tentang diare sebagian besar memiliki pengetahuan baik (62,79\%), responden yang memiliki pengetahuan cukup sebanyak $25,58 \%$ dan sebagian kecil responden $(11,63 \%)$ memiliki pengetahuan kurang. Kurang dari setengah responden (44,19\%) memiliki pengetahuan baik tentang tetanus neonatorum, lebih dari sepertiga responden $(37,21 \%)$ memiliki pengetahuan kurang dan sebanyak 18,60 persen responden memiliki pengetahuan cukup. Tingkat pengetahuan responden tentang pneumonia lebih banyak memiliki pengetahuan cukup $(48,84 \%)$ dan responden yang memiliki pengetahuan baik dan orang (40\%) cenderung memiliki

sikap positif. kurang relatif sama yaitu sebanyak 25,58 persen. Data pada Tabel 2 juga menunjukkan bahwa sebagian besar responden memiliki pengetahuan baik (62,79\%) tentang diare dan sebanyak 2,32 persen yang memiliki pengetahuan baik tentang ikterus. Responden yang memiliki pengetahuan cukup sebagian besar terdapat pada indikator pneumonia $(48,84 \%)$ dan 18,60 persen yang memiliki pengetahuan cukup tentang tetanus neonatorum. Responden yang memiliki pengetahuan kurang sebagian besar terdapat pada indikator ikterus $(69,77 \%)$ dan 11,63 persen yang memiliki pengetahuan kurang tentang hipotermi dan diare.

Tabel 3 menunjukkan bahwa sebagian besar responden $(58,14 \%)$ yang memiliki sikap positif dan sebanyak 41,86 persen responden yang memiliki sikap negatif.

Berdasarkan tabel 4, sebanyak 16 orang responden (80\%) yang memiliki pengetahuan baik cenderung memiliki sikap positif dan hanya 4 orang responden (20\%) yang memiliki pengetahuan baik memiliki kecenderungan sikap negatif. Sebanyak 11 orang $(61,2 \%)$ responden yang memiliki pengetahuan cukup cenderung memiliki sikap negatif, sedangkan responden yang memiliki pengetahuan cukup dengan kecenderungan sikap positif sebanyak 7 orang $(38,8 \%)$. Di antara responden yang memiliki pengetahuan kurang, sebanyak 3 orang $(60 \%)$ cenderung memiliki sikap negatif dan sisanya sebanyak 2

Tabel 1. Distribusi Pengetahuan Responden tentang Tanda Bahaya Neonatus di Puskesmas Karangasem II tahun 2013

\begin{tabular}{clccc}
\hline No & & Pengetahuan & Frekuensi (f) & Persentase \\
\hline 1 & Baik & & 22 & $51,16 \%$ \\
2 & Cukup & 16 & $37,21 \%$ & $11,63 \%$ \\
3 & Kurang & Total & 5 & $\mathbf{1 0 0 \%}$ \\
\hline
\end{tabular}

Tabel 2. Distribusi Pengetahuan Responden berdasarkan Indikator Tanda Bahaya Neonatus di Puskesmas Karangasem II tahun 2013

\begin{tabular}{|c|c|c|c|c|c|c|c|c|c|}
\hline \multirow[t]{2}{*}{ No } & \multirow[t]{2}{*}{ Indikator } & \multicolumn{2}{|c|}{ Baik } & \multicolumn{2}{|c|}{ Cukup } & \multicolumn{2}{|c|}{ Kurang } & \multicolumn{2}{|c|}{ Total } \\
\hline & & $f$ & $\%$ & $\mathbf{F}$ & $\%$ & $f$ & $\%$ & $f$ & $\%$ \\
\hline 1 & Hipotermi & 28 & 62,12 & 10 & 23,25 & 5 & 11,63 & 43 & 100 \\
\hline 2 & Ikterus & 1 & 2,32 & 12 & 27,91 & 30 & 69,77 & 43 & 100 \\
\hline 3 & Diare & 27 & 62,79 & 11 & 25,58 & 5 & 11,63 & 43 & 100 \\
\hline 4 & Tetanus Neonatorum & 19 & 44,19 & 8 & 18,60 & 16 & 37,21 & 43 & 100 \\
\hline 5 & Pneumonia & 11 & 25,58 & 21 & 48,84 & 11 & 25,58 & 43 & 100 \\
\hline
\end{tabular}

Tabel 3. Distribusi Sikap Responden tentang Tanda Bahaya Neonatus di Puskesmas Karangasem II tahun 2013

\begin{tabular}{cccc}
\hline No & Sikap & Frekuensi (f) & Persentase \\
\hline 1 & Positif & 25 & $58,14 \%$ \\
2 & Negatif & 18 & $41,86 \%$ \\
\hline & Total & 43 & $100 \%$ \\
\hline
\end{tabular}


Tabel 4. Tabulasi Silang antara Pengetahuan dengan Sikap Responden tentang Tanda Bahaya Neonatus di Puskesmas Karangasem II tahun 2013

\begin{tabular}{|c|c|c|c|c|c|c|c|}
\hline \multirow{3}{*}{ No } & \multirow{3}{*}{ Pengetahuan } & \multicolumn{4}{|c|}{ Sikap } & \multirow{3}{*}{ Total } & \multirow{3}{*}{$\%$} \\
\hline & & \multicolumn{2}{|c|}{ Positif } & \multicolumn{2}{|c|}{ Negatif } & & \\
\hline & & $\mathbf{F}$ & $\%$ & $\mathbf{F}$ & $\%$ & & \\
\hline 1 & Baik & 18 & 81,8 & 4 & 19,2 & 22 & 100 \\
\hline 2 & Cukup & 5 & 31,25 & 11 & 68,75 & 16 & 100 \\
\hline 3 & Kurang & 2 & 40 & 3 & 60 & 5 & 100 \\
\hline
\end{tabular}

\section{DISKUSI}

Berdasarkan tabel 1 didapatkan bahwa lebih dari setengah responden $(51,16 \%)$ memiliki pengetahuan baik tentang tanda bahaya neonatus dan sebagian kecil responden (11,63\%) memiliki pengetahuan kurang. Pengetahuan yang dimiliki oleh responden didapatkan dari petugas kesehatan di Puskesmas Karangasem II. Sesuai dengan protap Puskesmas Karangasem II yaitu setiap akhir rangkaian pemeriksaan pasien mempunyai hak untuk mendapatkan informasi kesehatan. Salah satu informasi yang diberikan adalah tanda bahaya neonatus terutama mengenai tanda dan gejala, penanganan serta dampak yang ditimbulkan. Pemberian informasi juga diberikan dalam bentuk penyuluhan yang dilakukan saat responden masih dirawat inap di Puskesmas tersebut, khususnya mengenai tanda bahaya neonatus. Penyuluhan ini biasanya dilakukan oleh petugas kesehatan. Ibu nifas juga diingatkan untuk membaca buku KIA karena dalam buku tersebut terdapat penjelasan mengenai perawatan bayi baru lahir serta tanda-tanda bayi sakit.

Sikap responden tentang tanda bahaya neonatus sebagian besar memiliki sikap positif $(58,14 \%)$. Reponden yang memiliki sikap negatif sebanyak 41,86 persen. Menurut Alport, sikap terdiri dari tiga komponen pokok yaitu keyakinan (kepercayaan), ide dan konsep seseorang terhadap objek, kehidupan emosional atau evaluasi emosional terhadap objek dan kecenderungan untuk bertindak ${ }^{9}$. Ketiga komponen ini secara berturut-turut membentuk sikap yang utuh pada seseorang. Sikap yang dimiliki oleh responden di mulai dari adanya

\section{PENUTUP}

\section{Simpulan}

Pada penelitian ini didapatkan:

1. Sebagian besar ibu nifas memiliki pengetahuan baik tentang tanda bahaya neonatus. Namun Secara spesifik, pengetahuan ibu nifas masih kurang pada ikterus neonatorum dan tetanus neonatorum. keyakinan (kepercayaan) terhadap pengetahuan yang dimiliki kemudian dituangkan dalam ide dan kehidupan emosional itu akan berpengaruh terhadap pengambilan keputusan dalam menentukan sikap yang akan dimiliki. Berdasarkan hasil penelitian didapatkan sebagian besar responden (51,16\%) memiliki pengetahun baik, sehingga sikap responden pun lebih banyak menunjukkan sikap positif. Hal ini sesuai dengan teori bahwa pengetahuan merupakan domain penting dalam membentuk sikap dan tindakan terhadap suatu hal ${ }^{4}$.

Berdasarkan hasil penelitian ini, pada kelompok ibu dengan pengetahuan baik, lebih dari setengah responden dengan pengetahuan baik cenderung memiliki sikap positif, yaitu sebanyak 81,8 persen. Sebaliknya, pada kelompok responden dengan pengetahuan cukup dan kurang, sebagian besar responden pada kelompok ini cenderung memiliki sikap negatif, berturut-turut pada kelompok cukup dan kurang sebesar 68,75 persen dan 60 persen. Notoatmodjo menyatakan bahwa untuk menimbulkan respon batin dalam bentuk sikap dari subjek terhadap objek yang diketahuinya, maka perlu di mulai dari domain kognitif (pengetahuan) ${ }^{7}$. Seseorang cenderung memiliki sikap positif apabila memiliki pengetahuan yang baik terhadap suatu hal. Hal ini juga membenarkan teori Notoatmodjo bahwa pembentukan sikap di mulai dari domain kognitif (pengetahuan), semakin tinggi pengetahuan responden tentang tanda bahaya neonatus maka pemahaman akan semakin meningkat sehingga semakin tepat dalam pengambilan sikap ${ }^{7}$.

2. Sikap ibu nifas tentang tanda bahaya neonatus sebagian besar memiliki sikap positif.

3. Kecenderungan sikap ibu nifas pada tanda bahaya neonatus bergantung pada tingkat pengetahuan dari masing-masing ibu nifas. Semakin baik tingkat pengetahuannya, sikap ibu nifas cenderung positif. 


\section{Saran}

Saran yang dapat diberikan kepada petugas pelaksana di Ruang KIA adalah agar mempertahankan dan meningkatkan pemberian informasi tentang tanda bahaya neonatus dengan menggunakan alat bantu berupa leaflet atau poster, terutama dalam hal ikterus neonatorum dan tetanus neonatorum. Informasi dan konseling tentang tanda bahaya neonatus sebaiknya diberikan saat pasien akan pulang. Kepada petugas pelaksana di Ruang Poliklinik Umum adalah agar mempertahankan dan meningkatkan penerapan Manajemen Terpadu Bayi Muda (MTBM) agar dapat

\section{DAFTAR PUSTAKA}

1. Hadijono, R.Soerjo. Asuhan Nifas Normal. Dalam: Saifuddin, AB, Rachimhadhi T, Wiknjosastro,GH, penyunting. Ilmu Kebidanan. Edisi keempat. Jakarta: Bina Pustaka Sarwono Prawirohardjo, 2008; h 356-358.

2. Depkes. Profil Kesehatan Indonesia, Jakarta: Depkes RI. 2007.

3. Depkes. Profil Kesehatan Provinsi Bali, Jakarta: t.p. 2009.

4. Depkes. Profil Kesehatan Kabupaten Karangasem, Jakarta: t.p. 2009. mendeteksi adanya tanda bahaya neonatus dengan cepat dan tepat. Sedangkan saran untuk dinas kesehatan adalah dapat menentukan program kesehatan atau penyuluhan yang tepat agar ibu nifas dapat memiliki pengetahuan yang baik dan angka kematian neonatus serta angka neonatus risiko tinggi dapat dikendalikan dan saran kepada peneliti selanjutnya adalah dapat melanjutkan penelitian dengan jumlah sampel yang lebih banyak serta menggunakan uji hubungan dengan wawancara yang lebih mendalam.

5. Hamzah, B. Perencanaan Pembelajaran, Jakarta: Bumi Aksara. 2006.

6. Notoatmodjo,S. Metodologi Penelitian Kesehatan, Jakarta: Rineka Cipta. 2005.

7. Notoatmodjo, S. Pendidikan dan Perilaku Kesehatan, Jakarta: Rineka Cipta. 2003.

8. Budiarto, E. Biostatistika untuk Kedokteran dan Kesehatan Masyarakat. Jakarta: EGC. 2002.

9. Notoatmodjo,S. Promosi Kesehatan dan IImu Perilaku, Jakarta: Rineka Cipta. 2007 